NBER WORKING PAPER SERIES

\title{
IS THE SUPPLY OF CHARITABLE DONATIONS FIXED? EVIDENCE FROM DEADLY TORNADOES
}

\author{
Tatyana Deryugina \\ Benjamin M. Marx \\ Working Paper 27078 \\ http://www.nber.org/papers/w27078 \\ NATIONAL BUREAU OF ECONOMIC RESEARCH \\ 1050 Massachusetts Avenue \\ Cambridge, MA 02138 \\ May 2020
}

We thank the Lilly Family School of Philanthropy for financial support. We thank Yuci Chen, Arash Farahani, Chitra Jogani, and Dana Shaat for excellent research assistance. We thank Maja Adena, Wojciech Kopczuk, Rob McClelland, Una Osili, Mark Ottoni-Wilhelm, Sarah Smith; seminar participants at Drexel University and the University of Illinois; and participants at the 2016 ASSA meetings, the 2016 ARNOVA Conference, the 2018 Science of Philanthropy Initiative Conference, the 2018 National Tax Association Annual Conference, and the 2020 MidMidwest Applied Microeconomics Workshop for their helpful comments. The views expressed herein are those of the authors and do not necessarily reflect the views of the National Bureau of Economic Research.

NBER working papers are circulated for discussion and comment purposes. They have not been peer-reviewed or been subject to the review by the NBER Board of Directors that accompanies official NBER publications.

(C) 2020 by Tatyana Deryugina and Benjamin M. Marx. All rights reserved. Short sections of text, not to exceed two paragraphs, may be quoted without explicit permission provided that full credit, including $\odot$ notice, is given to the source. 
Is the Supply of Charitable Donations Fixed? Evidence from Deadly Tornadoes

Tatyana Deryugina and Benjamin M. Marx

NBER Working Paper No. 27078

May 2020

JEL No. D64,L31,Q54

\section{$\underline{\text { ABSTRACT }}$}

Do new societal needs increase charitable giving or simply reallocate a fixed supply of donations? We study this question using IRS datasets and the natural experiment of deadly tornadoes. Among ZIP Codes located more than 20 miles away from a tornado's path, donations by households increase by over $\$ 1$ million per tornado fatality. We find no negative effects on charities located in these ZIP Codes, with a bootstrapped confidence interval that rejects substitution rates above 16 percent. The results imply that giving to one cause need not come at the expense of another.

Tatyana Deryugina

Department of Finance

University of Illinois at Urbana-Champaign

515 East Gregory Drive, MC-520

Champaign, IL 61820

and NBER

deryugin@illinois.edu

Benjamin M. Marx

Department of Economics

University of Illinois at Urbana-Champaign

214 David Kinley Hall, 1407 W. Gregory

Urbana, IL 61801

benmarx@illinois.edu 


\section{Introduction}

Charitable donations are an important source of funding for many public goods. For example, U.S. charitable giving makes up about 2 percent of GDP (List, 2011). Devolved funding responsibility creates costly competition for such funds, though, prompting many to ask whether charitable solicitations increase total giving or simply displace donations that would have gone to other causes. Indeed, the ratio of charitable donations to income has been fairly constant over time (Andreoni and Payne, 2013) and across income categories (Meer and Priday, 2020), and many laboratory experiments find that incentives to donate to one of a set of charities reduces giving to the others. 1 However, there are no estimates of such displacement effects that identify causal effects among a broad set of causes and a large share of annual donations.

We estimate whether exogenous increases in demand for donations created by fatal tornadoes-which vary over both space and time but are generally limited in their geographic scope-reduce other donations. Using ZIP-Code-level individual income tax data from the Internal Revenue Service (IRS), which include all income tax deductions claimed for donations to any registered charity, we find that lethal tornadoes significantly increase total charitable donations by individuals. In particular, conditional on a host of fixed effects, a tornado fatality increases total donations by more than $\$ 1$ million from individuals living in ZIP Codes located 20-100 miles away from a tornado's path. Because total giving increases, we can rule out perfect substitution between charitable causes and conclude that the supply of donations is not fixed.

We then test whether some donations made by donors in the areas surrounding a tornado's path come at the expense of these donors' local charities. To do so, we use data from information returns that charities file annually with the IRS. We show that contributions received by charities within 20 miles of a tornado's path increase by more

\footnotetext{
${ }^{1}$ See, for example, Reinstein (2012); Cairns and Slonim (2011); Reinstein (2011); Corazzini et al. (2015); Ek (2017); Filiz-Ozbay and Uler (2017); Deck and Murphy|(2019); Harwell et al. (2020); Schmitz (2019).
} 
than $\$ 1$ million. We then turn to our main question by testing for negative displacement effects on charities located more than 20 miles away. We find no statistically significant effects. The lack of effects cannot be attributed to insufficient precision, as we demonstrate by bootstrapping the ratio of the effects on local charities to the effects on total donations. The 95-percent confidence interval from our bootstrapping exercise rules out substitution from other charities in excess of 16 percent of the transfer to tornado victims. Finally, we use machine-learning methods to estimate treatment-effect heterogeneity among donors' local charities. We find no predictable negative effects on any particular types of charities.

Our study contributes to an active debate on the extent to which individuals substitute donations to one charity for donations to another ${ }^{2}$ In theory, increases in the number of charities or in the number of people served by a charity have ambiguously signed effects on donations (Rose-Ackerman, 1982, 1987). The supply of donations could also be completely fixed if giving exhibits "mental accounting" (Tversky and Kahneman, 1981, Kahneman and Tversky, 1984; Thaler, 1985, 1999). Field-study findings differ regarding whether intertemporal displacement does (Landry et al. 2010) ) or does not occur (Landry et al., 2010; Bekkers, 2015)) and whether displacement between causes does (Chatterjee et al. 2020) or does not occur (Meer, 2017) $3^{3}$ In a review of this literature, Gee and Meer (2019) conclude that "the evidence is decidedly mixed on whether the altruism budget is fixed or flexible."

Our paper addresses the question of substitution in giving with an unparalleled combination of strong internal validity and broad coverage of donors and causes ${ }_{4}^{4}$ Studies of

\footnotetext{
${ }^{2}$ Research has also provided highly credible experimental evidence about factors that increase charitable giving to a particular cause. Prominent examples include (List and Lucking-Reiley, 2002, Landry et al., 2006. Karlan and List, 2007; Shang and Croson, 2009;: Huck and Rasul, 2011: DellaVigna et al., 2012: Garbarino et al. 2013: Huck et al.. 2015; and Andreoni et al. 2017.

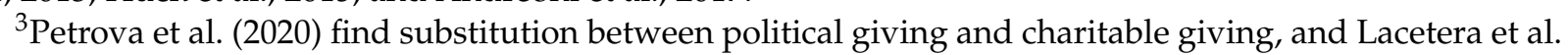
(2012) find that incentives to give blood in one location reduce giving in other locations. Adena and Hager (2020) find marginally significant displacement between related causes.

${ }^{4}$ Our use of individual income tax data follows the literature on the tax-price elasticity of charitable giving (Randolph. 1995; Auten et al., 2002; Bakija et al., 2003: Bakija and Heim, 2011). Our use of the information returns that nonprofit organizations file with the government follows studies estimating the effects of government grants on charities' fundraising efforts (Andreoni and Payne, 2003, 2011).
} 
giving to international disasters (e.g. Brown and Minty, 2008; Scharf et al., 2017) have necessarily relied on time-series variation because there is no untreated control group at any point in time, whereas the local nature of tornadoes allows us to define treatment and control groups and estimate relative changes among the treated. Experimental studies provide strong internal validity but have estimated substitution patterns only between a small set of charities. Experimental estimates may also not generalize if patterns of donating from an experimental endowment differ from patterns of donations from general income (Cherry et al., 2002; Reinstein and Riener, 2012; Carlsson et al., 2013; Drouvelis et al. 2019) or if subjects are induced to adjust the donations they make outside of the experiment. In contrast, we observe donations to the full spectrum of causes, allowing us to detect a wide variety of substitution patterns, if they exist. Our paper is the first to employ datasets that contain the majority of dollars donated across the U.S. and the first to identify effects using a natural experiment with both geographic and temporal variation.

We also contribute to the empirical literature on financial assistance in the aftermath of natural disasters. Charitable giving for natural disasters is common, with a nationally representative survey indicating that about 30 percent of U.S. households made such donations in each of 2017 and 2018 (Bergdoll et al., 2019). Nearly 80 percent of these households claim that their disaster giving did not affect their giving to other causes, but survey respondents may be reluctant to admit that they reduced charitable giving to other causes. Yet much of the literature focuses on the determinants of domestic or foreign disaster aid (e.g. Besley and Burgess, 2002; Garrett and Sobel, 2003; Drury et al., 2005; Eisensee and Strömberg, 2007; Strömberg, 2007; Healy and Malhotra, 2009; Cole et al., 2012: Deryugina and Kirwan, 2018). To the best of our knowledge, our paper is the first to quantify the charitable response to tornadoes and the first to quantify donations for any type of disaster using administrative data. 5

The rest of the paper is organized as follows. In Section 2 we describe our data. In

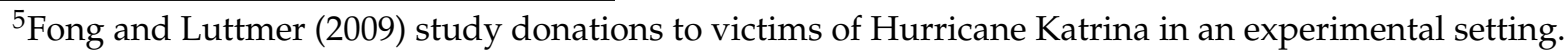


Section 3 we lay out our empirical strategy for estimating the effects of tornadoes near the locations in which they strike and in locations that are further away. In Section 4 we report our results. We conclude in Section 5 .

\section{Data}

\subsection{Tornadoes}

Tornadoes are rotating columns of air that form during strong thunderstorms. Winds can reach up to 300 miles per hour, causing catastrophic damage to structures with which a tornado comes in contact. Tornadoes are common in the U.S., but most are local and short-lived, have much weaker winds, and do not harm people or buildings. While the majority of tornadoes affect regions of the South and Midwest known as "Tornado Alley," tornadoes have been observed in every U.S. state.

Our data on tornadoes come from the National Oceanic and Atmospheric Administration's (NOAA) Tornado Database, which tracks the path of every known tornado since 1950 $\sqrt[6]{6}$ In addition to providing the starting and ending coordinates of each tornado along with the date and time when it occurred, the database contains the number of reported fatalities and injuries for each tornado. We use the number of fatalities to identify tornadoes that are likely to generate a charitable giving response. 7

Figure 1 displays the paths of every tornado that formed in 2002-2017 and caused at least one fatality. It also displays the total number of fatalities by state. Three key patterns emerge. First, fatal tornado strikes are concentrated in the Midwest and the South. Second, deadly tornadoes have struck across a wide range of most of the states in which they have occurred. Third, tornadoes are local events, with even the most lethal

\footnotetext{
${ }^{6}$ Available from http://www.spc.noaa.gov/wcm/\#data

${ }^{7}$ The database also provides estimates of damage, but these are very imprecise and are thus much noisier measures of severity than fatalities. For example, uncertain damage is recorded as zero damage and there is no way to distinguish it from true zeroes. While injuries may also indicate severity, no distinction is made between minor and major injuries, making them less comparable to each other than fatalities.
} 
rarely passing through more than a handful of counties. Appendix Figure A.1 shows that tornado casualties occur throughout the year but are most prevalent in April and May 8

Figure 1: Fatal tornadoes in the United States, 2002-2017

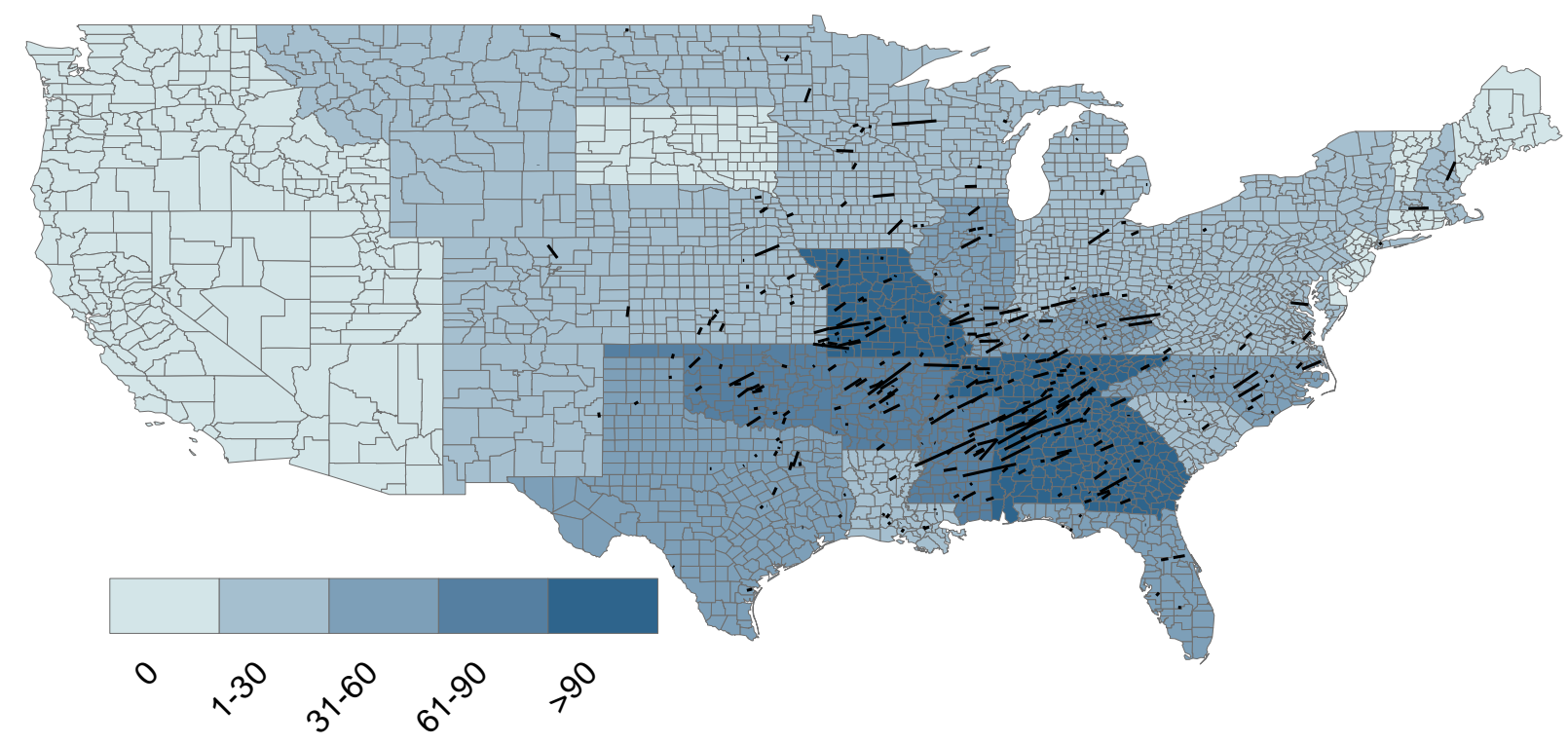

Source: NOAA. Black markers represent tornadoes that occurred in 2002-2017 and caused at least one fatality. Colors represent total tornado-caused fatalities in a state during the period 2002-2017.

\subsection{Income tax data on charitable donations to all causes}

Annual data on charitable donations come from the IRS.9 The data are based on individual income tax returns, including all Forms 1040, 1040A, and 1040EZ. They report deductions claimed for charitable donations in 2002 and in 2004-2017. Returns are compiled by filing year, providing totals based mostly on the preceding tax year but including some late returns for the previous tax year. Data are aggregated by the ZIP Code listed

\footnotetext{
${ }_{8}$ Scharf et al. (2017) find that natural disasters have short-run time-shifting effects on donations to other charities but find no net effect over a 20-week period. That most deadly tornadoes occur in first half of the year therefore suggests that our estimates using annual data should capture full net effects.

${ }^{9}$ Available from https://www.irs.gov/statistics/soi-tax-stats-individual-income-tax-statistics-zip-codedata-soi.
} 
on the return, which is usually the ZIP Code of the taxpayer's home address but could alternatively be the address of a lawyer, accountant, or place of business.

The IRS has taken varying steps to avoid disclosure of information about individual taxpayers. ZIP Codes with fewer than a threshold number of returns (ten returns in most years) were excluded. We restrict our sample in all years to satisfy the most stringent threshold of at least 250 returns.

The main variable of interest is the total amount of charitable contributions claimed for tax deductions. We also make use of the number of tax returns that include such deductions, the total number of returns, and total Adjusted Gross Income (AGI). Because IRS disclosure rules prevent us from distinguishing true zeroes in the data from censored values, we restrict the sample to ZIP Codes for which charitable contributions are always strictly positive.

\subsection{IRS Form 990 data on receipts of charities}

The data for charities have been collected by the IRS using Form 990, the annual information return that most charities are required to file. ${ }^{10}$ Data are available for the years 1998-2016, but we drop years prior to 2002 for comparability with the individual income tax data. Our main variable of interest is contributions, which is the sum of donations from individuals, gifts, and grants.

These data are known to contain many duplicates. Therefore, we keep only one entry when we find matches on the Employer Identification Number (EIN) and fiscal year that also match on any of assets, contributions, expenses, or gross receipts. Whenever the financial variables disagree in such cases, we keep the entry from the most recent data file. We also address location discrepancies that are likely to be errors. If a charity's ZIP Code in year $t-1$ matches that in year $t+1$ but not in year $t$, we replace the ZIP Code in period $t$ so that it is consistent over time. We then replace the ZIP Code with our time-

\footnotetext{
${ }^{10}$ We obtain the data from the Urban Institute (https://nccs-data.urban.org/data.php?ds=core).
} 
invariant "super-ZIP", which we discuss below. Finally, we replace the reported state with the state to which the super-ZIP belongs using the 2010 Esri ZIP Code centroids file.

We also address likely reporting errors. First, we drop observations with reported gross receipts (i.e. contributions) that are zero or negative. We also determine each organization's maximum absolute-value year-over-year change in log contributions, and we drop the one percent of organizations that exhibit the largest changes. This step addresses reporting errors such as reporting in thousands of dollars instead of dollars or writing values on the wrong line of the form.

Because the fiscal cycles of public charities do not always overlap with calendar years, we match the tornado data to each charity's fiscal cycle by month and ZIP Code and then aggregate to the annual level using the year in which the fiscal year ends.

\subsection{ZIP Codes}

Our geographic unit of analysis is a ZIP Code Tabulation Area (ZCTA). ZCTAs are a trademark of the U.S. Census Bureau and provide a spatial representation of the mailing areas covered by ZIP Codes ${ }^{11}$ Hereafter, we simply refer to ZCTAs as ZIP Codes. For the latitudes and longitudes of their locations, we use the 2010 Esri ZIP Code centroids file, which corresponds to the median year in our donations data.

We use data from the U.S. Postal Service to account for changes in the coverage of ZIP Codes over time. Each month, the USPS produces a Postal Bulletin that includes a table of changes to ZIP Code delivery areas. $\sqrt[12]{12}$ The most common changes are creations of new ZIP Codes for part of an area previously covered by another ZIP Code and elimination of ZIP Codes when a post office is closed. Each change reports two ZIP Codes, which we combine with each other and with all other ZIP Codes to which they are connected

\footnotetext{
${ }^{11}$ For details, see https://www.census.gov/programs-surveys/geography/guidance/geoareas/zctas.html

${ }^{12}$ Postal Bulletins are available for download at https:// postalpro.usps.com/postal-bulletin-changes and https://ribbs.usps.gov/postalbulletinchanges/postalbulletinchanges_print.htm
} 
through one or more changes, to create a set of time-invariant "super-ZIPs." We aggregate our other datasets to the super-ZIP level by summing all financial variables over the ZIP Codes included in the super-ZIP. For the latitude and longitude of a super-ZIP we take the average of the values of the included ZIP Codes, a simplification that suffices for our designs, which do not require that we distinguish between distances of less than 10 miles. Hereafter, we simply refer to these super-ZIPs as ZIP Codes.

We calculate the distance between ZIP Codes and tornadoes using latitude and longitude. These coordinates are available for both the start point and end point of each tornado. We therefore calculate the shortest distance, in miles, between each ZIP Code and the line segment connecting the starting and ending points of the tornado 13 This will create some degree of mismeasurement because tornadoes do not necessarily travel in straight lines, but our design does not depend on finely measured distances. Similarly, we do not know the exact locations of fatalities, but we can sum all fatalities caused by tornadoes that passed within a range of distances, such as between 10 and 20 miles from a given ZIP Code. 14

\subsection{Summary statistics}

Table 1 provides summary statistics for each of our main datasets. Panel A displays statistics for deadly tornadoes in the United States that occurred between 2002 and 2017. On average, a fatal tornado injured 34 people and caused property damage of almost 1.2 million dollars. Tornado severity varies considerably; the worst tornado in our sample period killed 158 people, but the median lethal tornado killed two people.

Panel B of Table 1 shows summary statistics for the individual income tax data at the ZIP-Code-year level. Each observation includes at least 250 tax returns, reflecting the

\footnotetext{
${ }^{13}$ More precisely, we create 1,000 points between the start and end points of the tornado and use the minimum of the distances between these points and a ZIP Code centroid.

${ }^{14}$ Fatalities are reported at the tornado level. If a tornado affects multiple states, we divide fatalities equally among the affected states (usually two). In some cases, this yields fractional fatalities.
} 
Table 1: Summary statistics

Mean Std. Min. MedianMax. N

Dev.

Panel A: Fatal tornadoes

\begin{tabular}{lcccccc}
\hline Injuries & 33.88 & 113.3 & 0 & 8 & 1500 & 337 \\
Fatalities & 3.96 & 10.6 & 1 & 2 & 158 & 337 \\
Property damage (mill.) & 1.19 & 17.0 & 0 & 0 & 310 & 337 \\
Crop losses (thou.) & 5.73 & 63.6 & 0 & 0 & 850 & 337 \\
\hline
\end{tabular}

Panel B: Income tax data

\begin{tabular}{lcccccc}
\hline Returns filed (thous.) & 5.39 & 6.8 & 0.25 & 2.2 & 121 & 354,648 \\
No. of returns with charitable donations (thous.) & 1.48 & 2.2 & 0.01 & 0.4 & 32 & 329,810 \\
Charitable donations (mill.) & 7.54 & 17.6 & 0.00 & 1.8 & 1489 & 354,648 \\
Charitable donations per return (thous.) & 1.18 & 2.6 & 0.00 & 0.8 & 473 & 354,648 \\
Adjust Gross Income per return (thous.) & 55.06 & 45.5 & - & 45.9 & 5711 & 354,648 \\
& & & 15.00 & & & \\
Fatalities, 0-20 miles & 0.14 & 2.5 & 0.00 & 0.0 & 158 & 354,648 \\
Fatalities, 20-100 miles & 1.33 & 9.5 & 0.00 & 0.0 & 266 & 354,648 \\
In-state fatalities, 20-100 miles & 0.74 & 5.6 & 0.00 & 0.0 & 185 & 354,648 \\
In-state fatalities, 20+ miles & 2.04 & 10.4 & 0.00 & 0.0 & 187 & 354,648 \\
\hline
\end{tabular}

Panel C: Charities data

\begin{tabular}{lcccccc}
\hline Contributions received (mill.) & 1.4 & 20.5 & 0 & 0.09 & 7613 & $3,228,283$ \\
Total revenue (mill.) & 7.8 & 193.2 & -15 & 0.23 & 93407 & $3,228,281$ \\
Total expenses (mill.) & 5.3 & 67.0 & 0 & 0.18 & 11102 & $3,228,283$ \\
Fatalities, 0-20 miles & 0.1 & 2.2 & 0 & 0.00 & 158 & $3,228,283$ \\
Fatalities, 20-100 miles & 1.0 & 8.3 & 0 & 0.00 & 266 & $3,228,283$ \\
In-state fatalities, 20-100 miles & 0.2 & 2.8 & -158 & 0.00 & 162 & $3,228,283$ \\
In-state fatalities, 20+ miles & 1.6 & 8.8 & 0 & 0.00 & 190 & $3,228,283$ \\
\hline
\end{tabular}

Notes: Sources are the National Oceanic and Atmospheric Administration's Tornado Database, the Internal Revenue Service, and the National Center for Charitable Statistics. Unit of observation in panel A is a tornado. Unit of observation in panel B is ZIP-Code-year. Unit of observation in Panel C is EIN-year. Dollar values are inflation-adjusted to 2017 dollars. Panel A includes years 2002-2017. Panel B includes years 2002 and 2004-2017. Panel C includes years 2002-2016 
sample restriction, and covers over 5,000 returns on average. When observed, the number of returns with charitable donations was roughly one quarter of the total number of returns $\sqrt{15}$ On a per-return basis, charitable donations average about $\$ 1,000$, or roughly 2 percent of the average income of $\$ 55,000$, consistent with the common finding that charitable giving accounts for 2 percent of income in the U.S. (e.g. Andreoni and Payne 2013). On average, there are about 1.3 fatalities caused by tornadoes that struck within 100 miles of ZIP Codes for which we have income tax data and another 1.3 caused by tornadoes that struck other parts of the state that are at least 100 miles away.

Panel C of Table 1 displays summary statistics for charity-year observations. Contributions exceed $\$ 1$ million on average but are closer to $\$ 100,000$ at the median. Total revenues, which include contributions, are several times larger than contributions and are highly variable across observations. Expenses are roughly 70 to 80 percent of revenues. The mean values of the tornado variables are slightly smaller than the means displayed in Panel B, indicating that the average charity is located in an area near somewhat fewer serious tornadoes than the average taxpayer, though they also experience an average of one fatality per year caused by tornadoes passing within 100 miles.

\section{Empirical strategy}

\subsection{Conceptual framework}

The IRS collects data on the amount of charitable donations but not the causes to which households give. This makes it impossible to test how tornadoes affect giving from particular households to particular causes. For areas that are not themselves struck by tornadoes, though, the two IRS datasets described above allow us to recover the share of tornado-related donations that would have been made to other causes if not for a deadly

\footnotetext{
${ }^{15}$ Whether a return claims any charitable deductions was not reported in 2008.
} 
tornado 16

Consider individuals in location $j$. Denote by $F_{j}$ the number of tornado fatalities occurring within a distance band of that location, such as 20-100 miles. Individuals in $j$ give an amount $\ell_{j}\left(F_{j}\right)$ to local charities in or near $j$ and give $n_{j}\left(F_{j}\right)$ to national charities and charities in the locations of tornado victims. Denote the effects of one additional tornado fatality as $\triangle \ell_{j}:=\ell_{j}\left(F_{j}+1\right)-\ell_{j}\left(F_{j}\right)$ and $\triangle n_{j}:=n_{j}\left(F_{j}+1\right)-n_{j}\left(F_{j}\right)$.

In the income-tax data, we observe donations from households in $j$ to all causes, allowing us to estimate $\Delta \ell_{j}+\Delta n_{j}$. In the information returns filed by charities, we observe donations to charities located in $j$, which will include $\ell_{j}\left(F_{j}\right)$ and possibly donations from individuals in other locations $k \neq j$. We assume that if location $j$ is far enough from a tornado such that its local charities are plausibly not involved in relief efforts, then the tornado does not increase donations of individuals in $k$ to charities that are local to $j$. Displacement effects of tornadoes are therefore less than or equal to $\triangle \ell_{j}$, which can be estimated using changes in donations received by charities in location $j$. The ratio of the change in receipts of these charities to the change in donations on individual tax returns yields an estimate of $\frac{\Delta \ell_{j}}{\Delta \ell_{j}+\Delta n_{j}}$, which is easily transformed into $\frac{\Delta \ell_{j}}{\Delta n_{j}}$, the (negative of the) share of dollars going to support tornado victims that otherwise would have been given to local charities.

While our research design improves on those used in prior studies, in which subjects can often choose between only a limited number of charities, it does have some limitations. Regarding the income tax data, the primary limitation is that not all donations are claimed for tax deductions, primarily because not all individuals itemize their deductions. Income tax data will therefore likely underestimate the total change in individual donations in response to tornadoes, making our estimate of the substitution ratio an up-

\footnotetext{
${ }^{16}$ We focus on areas that are not themselves struck by tornadoes because charitable-giving responses in directly affected areas are difficult to predict. For example, tornadoes may have negative income effects in areas where they strike and/or generate a large in-kind giving response, which we cannot measure with our data.
} 
per bound 17 We acknowledge several caveats for working with the charity data. First, our estimates will be biased against finding displacement if organizations located more than 20 miles from a tornado serve its victims. While we think this is unlikely to be the case for relatively small charities, we also test for this issue by dropping larger organizations that may operate in multiple locations and by testing for heterogeneity by charity type. Second, our spatial design will not capture any negative effects on national organizations that are not serving tornado victims. Similarly, while donations to religious congregations can be deducted and so should appear in the income tax data, congregations are not required to file information returns. Even if there are displacement effects on either of these types of organizations that differ from those we can measure, our design still provides unbiased estimates of the displacement effect for local charities. Third, a portion of the literature has examined substitution between donating and volunteering (e.g. Brown et al.|2019), and we do not capture volunteering or informal giving that does not pass through charitable organizations. However, we expect that volunteering for and informal giving to tornado victims living more than 20 miles away is limited.

\subsection{Estimation approach}

Even for locations in "tornado alley," tornadoes are unpredictable (Simon, 2019). Based on this unpredictability, our identification assumption is that, conditional on location and time fixed effects, the number of fatalities caused by tornadoes is unrelated to other determinants of charitable giving. To estimate the effects of tornadoes on charitable giving, we estimate the following equation:

$$
\operatorname{asinh}\left(d_{i t}\right)=\beta * \operatorname{asinh}\left(\text { fatalities }_{i t}^{b}\right)+\boldsymbol{X}_{i t}+\alpha_{i}+\alpha_{t}+\varepsilon_{i t} .
$$

\footnotetext{
${ }^{17}$ Alternatively, we might overestimate the total charitable response by individuals if tornadoes cause individuals who would have given but not claimed deductions to start claiming deductions. Appendix Table A.1 shows, however, that we do not find significant effects on the number of returns claiming charitable deductions.
} 
In this equation, $t$ is the year, and the unit of observation $i$ is a ZIP Code when using the income tax data and a charity when using the charity data. The outcome is $\operatorname{asinh}\left(d_{i t}\right)$, the inverse hyperbolic sine (asinh) of charitable donations for unit $i$ in year $t$. The variable of interest is $\operatorname{asinh}\left(\right.$ fatalities $\left._{i t}^{b}\right)$, the inverse hyperbolic sine of fatalities caused by tornadoes that struck within a band of distances indexed by $b$.

The variation in tornadoes would not be plausibly random if we did not estimate effects within a location. Equation (1) therefore includes controls for unit and year fixed effects, $\alpha_{i}$ and $\alpha_{t}$, respectively. Time-varying controls $X_{i t}$ improve the precision of our estimates. We include 3-digit-ZIP time trends in all regressions. When using the charity data, we control for EIN-by-ZIP Code fixed effects. When using the income tax data, we control for cubic functions of the number of tax returns and total AGI, both of which we show to be unaffected by tornadoes (Appendix Table A.2). We also control for year fixed effects for each ventile of AGI 18

Donors may have greater affinity for victims in their own states. To allow for this, we use three measures of fatalities $_{i t}$ : Fatalities caused by tornadoes that struck (a) 20-100 miles away, (b) 20-100 miles away and within the same state, and (c) 20+ miles away and within the same state. Throughout, we report standard errors that are clustered at the state level.

\section{Results}

\subsection{Donations made to all causes}

The results reported in Table 2 show that deadly tornadoes significantly increase total donations to all causes. Our first measure is the number of fatalities caused by tornadoes that struck within 20-100 miles of donors' ZIP Codes (columns 1-2). We obtain a larger es-

\footnotetext{
${ }^{18}$ We use AGI in the observed year closest to 2010, the midpoint of our sample, using the later year in cases of ties.
} 
Table 2: The effect of tornadoes on donations to all causes (income tax data)

\begin{tabular}{|c|c|c|c|c|c|c|}
\hline & (1) & (2) & (3) & (4) & (5) & (6) \\
\hline Fatalities, 20-100 miles & $\begin{array}{c}0.0018 \\
(0.0009)^{* *}\end{array}$ & $\begin{array}{c}0.0017 \\
(0.0008)^{* * *}\end{array}$ & & & & \\
\hline Fatalities, 0-20 miles & & $\begin{array}{c}0.0007 \\
(0.0014)\end{array}$ & & & & \\
\hline In-state fatalities, $20-100$ miles & & & $\begin{array}{c}0.0030 \\
(0.0013)^{* *}\end{array}$ & $\begin{array}{c}0.0029 \\
(0.0012)^{* *}\end{array}$ & & \\
\hline In-state fatalities, $20+$ miles & & & & & $\begin{array}{c}0.0025 \\
(0.0010)^{* *}\end{array}$ & $\begin{array}{c}0.0024 \\
(0.0010)^{* *}\end{array}$ \\
\hline In-state fatalities, 0-20 miles & & & & $\begin{array}{c}0.0011 \\
(0.0013)\end{array}$ & & $\begin{array}{c}0.0013 \\
(0.0014)\end{array}$ \\
\hline Observations & 354,457 & 354,457 & 354,457 & 354,457 & 354,457 & 354,457 \\
\hline AIC & -286506 & -286505 & -286530 & -286529 & -286548 & -286547 \\
\hline Effect ( $\$ 1000$ s) of add'1. fatality & 1025 & 994.6 & 1210 & 1171 & 1908 & 1863 \\
\hline Standard error of add'l. fatality & 492.6 & 465.2 & 514.2 & 488.9 & 790 & 763.9 \\
\hline
\end{tabular}

Notes: The table reports estimates of equation (1). The dependent variable is the inverse hyperbolic sine of donations. Standard errors (in parentheses) are clustered by state. ${ }^{* * *} \mathrm{p}<0.01,{ }^{* *} \mathrm{p}<0.05,{ }^{*} \mathrm{p}<0.10$.

timate and a larger t-statistic when estimating the effects of only the tornadoes that struck within a donors' own state (columns 3-4), suggesting heightened affinity or media exposure. The point estimate is smaller for fatalities caused by tornadoes that struck at least 20 miles away but within the same state (columns 5-6) - consistent with a response that declines as distance increases-but this measure also produces a large t-statistic. Results reported in even-numbered columns show that controlling for tornado fatalities within 20 miles has little effect on our estimates and does not reduce the AIC.

The coefficients from the asinh-asinh specification can be interpreted as approximate elasticities, where elasticities evaluated at mean values would be somewhat smaller than the estimates because the regressor has a smaller mean than the regressand (Bellemare and Wichman, forthcoming). Thus, a one percent increase in fatalities increases donations by up to 0.003 percent, depending on the measure of fatalities. Elasticities are small because we are studying changes in giving to all types of organizations, most of which 
do not serve tornado victims.

To provide a clearer measure of the size of the response, we perform a calculation to convert our estimates into an average dollar value per tornado fatality. To do so, we use the estimate to determine the predicted change in contributions if each of the fatal tornadoes in the sample were to have caused one additional fatality. This procedure accounts for the fact that deadly tornadoes are not evenly distributed across the country and that ZIP Code exposure may be correlated with ZIP Code mean annual charitable donations. We average the effects of these counterfactual tornadoes to obtain a per-fatality estimate and include these dollar-valued effects (along with standard errors calculated using the delta method) at the bottom of Table 2 .

We find that the charitable response to deadly tornadoes is sizeable. Each fatality increases donations from ZIP Codes that are 20-100 miles away by roughly $\$ 1$ million. If we include the entire state that was struck, as in column (3) of the table, we find that the response is nearly $\$ 2$ million dollars. For context, each tornado fatality in our sample is associated with roughly 8.2 injuries and reported property damage of $\$ 18.5$ million. We can also benchmark the estimated charitable response against the amount of federal disaster aid received for tornado-related disasters in the years 2004-2017 19 Dividing the total state-year disaster aid by the corresponding number of fatalities, we obtain a mean amount of aid of $\$ 13.3$ million per fatality and a median of $\$ 2.98$ million per fatality (2008 dollars).

Appendix tables present additional robustness tests of our analysis with the income tax data. The results of a placebo test reported in Appendix Table A.3 show no evidence of any effects of the lead of the fatalities measures. As can be seen in Appendix Table A.4, the results are not affected by restricting the sample period to years prior to 2017, for which we have data from charitable organizations. Because giving to tornado victims may affect future giving, which could affect our estimates of concurrent effects, we test whether lags

\footnotetext{
${ }^{19}$ These data were obtained from https://www.fema.gov/disasters
} 
of the tornado severity variable are themselves significant or alter our estimates of the contemporaneous effect. The results reported in Appendix Table A.5 show that tornadoes have persistent effects in areas within 20 miles, but estimates for greater distances are not statistically significant.

Without any further evidence, we can conclude that deadly tornadoes increase giving and do not merely divert it from other causes. If individuals merely shifted money between charities, then we would find no effects on the total amount donated. The significant effects on total giving in the income tax data therefore bound the substitution rate below one. To estimate whether any substitution between causes occurs, we now turn to the data for contributions received by charities.

\subsection{Contributions received by charities}

In this section, we estimate equation (1) using the charity data. We do so first for charities that are local to a disaster site to confirm that charitable responses can be detected with the charities dataset. We then test for negative effects on charities that are located further away, in locations in which we observed an increase in donations in the income tax data.

In Table 3 we report the estimated effects on charities near a tornado site. We find significant positive effects on charities located within 10 miles of a tornado. The estimate for charities located 10-20 miles away is also positive but is not significant, and it does not lower the AIC. We find this same pattern whether we consider all tornadoes (columns 1-2) or simply those that struck within the state where a charity is located (columns 3-4). The results indicate that most of the charities whose contributions increase are located within 10 miles of a tornado, but to be conservative in our subsequent analysis of more distant areas, we restrict our attention to distances of at least 20 miles, as we did with the income tax data.

Calculating dollar-value effects as we did with the income tax data, we find that, on average, an additional fatality increases donations to local charities by $\$ 1.2$ million. The 
Table 3: The effect of tornadoes on contributions received by local charities (charities tax data)

\begin{tabular}{|c|c|c|c|c|}
\hline & (1) & (2) & (3) & (4) \\
\hline Fatalities within $0-10$ miles & $\begin{array}{c}0.0115 \\
(0.0033)^{* * * *}\end{array}$ & $\begin{array}{c}0.0108 \\
(0.0034)^{* * *}\end{array}$ & & \\
\hline Fatalities in $10-20$ miles & & $\begin{array}{c}0.0037 \\
(0.0034)\end{array}$ & & \\
\hline In-state fatalities, $0-10$ miles & & & $\begin{array}{c}0.0130 \\
(0.0035)^{* * * *}\end{array}$ & $\begin{array}{c}0.0124 \\
(0.0035)^{* * * *}\end{array}$ \\
\hline In-state fatalities in 10-20 miles & & & & $\begin{array}{c}0.0038 \\
(0.0033)\end{array}$ \\
\hline Observations & $3,228,283$ & $3,228,283$ & $3,228,283$ & $3,228,283$ \\
\hline AIC & $9.340 \mathrm{e}+06$ & & $9.340 \mathrm{e}+06$ & \\
\hline Relative AIC & & 0.116 & & 0.0295 \\
\hline Effect (\$1000s) of add'l. fatality & 1144 & 1079 & 1244 & 1183 \\
\hline Standard error of add'l. fatality & 329.3 & 334.5 & 334.4 & 338.8 \\
\hline
\end{tabular}

Notes: The table reports estimates of equation (1). The dependent variable is the inverse hyperbolic sine of contributions received. Standard errors (in parentheses) are clustered by state. ${ }^{* * *} \mathrm{p}<0.01,{ }^{* *} \mathrm{p}<0.05$, ${ }^{*} \mathrm{p}<0.10$. 
magnitude of this effect is comparable to what we find in the individual income tax data, corroborating our earlier finding 20

Having estimated an increase in contributions to charities near a tornado, we turn to our main question regarding the degree to which contributions decrease among charities located further away from a tornado. Our estimates appear in Table 4 For each of the measures of severe tornadoes that predicted a significant charitable response in the income tax data, we find that effects on donors' local charities are insignificant and the point estimates are positive rather than negative. Thus, it does not appear that these charities lose out to those serving tornado victims.

The results reported in Appendix Table A.6 show that our results are similar when we drop observations from 2003, for which charitable giving is not reported in the income tax data. For another robustness check, we drop larger charities that are more likely to serve individuals outside of their own areas. Appendix Table A.7 shows that the results are consistent across samples restricted by size.

We also test for heterogeneous treatment effects to see whether some charities are negatively affected. First, we interact our tornado variables with dummy variables for charity missions, as categorized by the National Taxonomy of Exempt Organizations (Appendix Table A.8. If mission similarity were to make charities closer substitutes, we might find negative effects on charities in the "Human Services" or "Public Safety, Disaster Preparedness Relief" categories. We find no negative effects in these categories. Second, we conduct a more general test of heterogeneous treatment effects using machine learning, following Chernozhukov et al. (2018). We allow treatment effects to vary across charity missions or size and across ZIP Code demographics. Details and results appear in Appendix B. We find no evidence of predictable heterogeneity.

\footnotetext{
${ }^{20}$ We would not necessarily expect the two effects to be the same because the income tax estimate includes donations to national organizations, and the estimate for charities includes local donations and may include grants from foundations or governments.
} 
Table 4: The effect of tornadoes on contributions received by distant charities (charities tax data)

(1) (2)

\begin{tabular}{lccc}
\hline Fatalities within 20-100 miles & 0.0014 & & \\
In-state fatalities, 20-100 miles & $(0.0012)$ & 0.0000 & \\
& & $(0.0011)$ & 0.0010 \\
In-state fatalities, 20+ miles & & & $(0.0012)$ \\
& & & \\
\hline Observations & $3,162,513$ & $3,162,513$ & $3,162,513$ \\
Effect $(\$ 1000$ s) of add'1. fatality & 1133 & 5.394 & 1004 \\
Standard error of add'l. fatality & 959.7 & 244 & 1241 \\
\hline
\end{tabular}

Notes: The table reports estimates of equation (1). The dependent variable is the inverse hyperbolic sine of contributions received. Standard errors (in parentheses) are clustered by state. ${ }^{* * *} \mathrm{p}<0.01,{ }^{* *} \mathrm{p}<0.05$, ${ }^{*} \mathrm{p}<0.10$.

\subsection{Substitution ratio}

We find no significant negative effects of deadly tornadoes on charities in surrounding areas, but this statistical zero could reflect a lack of statistical precision rather than a true lack of substitution. We address this concern by bootstrapping and subsequently examining the distribution of the ratio of the effects in the charity data relative to that in the income tax data.

Because of likely spatial correlation in the receipts of charities and the donations of nearby individuals, we use a cluster bootstrap approach. That is, we draw with replacement from the 49 contiguous "states" (including Washington, D.C.) and include all observations in each dataset and all years for these states. We estimate the effects of tornadoes in each dataset using a specification that includes state time trends, which provide most of the precision obtainable with 3-digit-ZIP time trends but are less computationally intensive. For our measure of lethality, we use in-state fatalities from tornadoes that struck 20-100 miles away, which is the variable that yielded the most precise results. As before, we calculate the dollar-value effects of a one-fatality increase in each dataset, for each of 
10,000 bootstrap draws. We then divide each estimate of dollar-value effects on charities by the effect on total donations for the same sample of states.

Appendix Figure A.2 displays the distribution of bootstrapped donation ratios ${ }^{21}$ Our 5th-percentile estimate is -0.1888 . If $\frac{\Delta \ell_{j t}}{\triangle \ell_{j t}+\triangle n_{j t}}=-0.1888$, then $\frac{\triangle \ell_{j t}}{\triangle n_{j t}}=\frac{-0.1888}{1+0.1888}=-0.159$, implying that we can rule out substitution between causes that exceeds 16 percent of the charitable response. Fewer than 12 percent of the estimates are negative. We therefore conclude that our failure to find displacement effects cannot be attributed to a lack of statistical power.

\section{Conclusion}

The social value of charitable giving and the optimal subsidies to donors and charitable organizations depend on whether increases in giving to one cause come at the expense of other causes. We use comprehensive annual tax return data to estimate whether tornadoes increase total charitable giving, and we find that each tornado fatality increases total donations by over $\$ 1$ million. Therefore, we can rule out that individuals choose a set amount to donate to charity and then apportion this between charities. Using annual tax return data from charities, we additionally find that there are no significant negative effects on charities in the locations from which increased donations to fatal tornadoes originate. Our results are sufficiently precise to rule out an average displacement effect that is greater than 16 percent of the total charitable response.

There is an active debate in research regarding the extent of donor substitution between charitable causes. Our paper is the first in this literature to employ a natural experiment with both geographic and temporal variation and the first to employ datasets that contain the majority of dollars donated across the U.S. Our finding that deadly tornadoes increase charitable giving and do not simply redirect donations from other causes seems

\footnotetext{
${ }^{21}$ Because the goal of this exercise is to assess the precision of our charity data estimate relative to the increase in total giving, we drop 352 draws in which the estimated effects in the income tax data are negative.
} 
likely to generalize to other situations in which new needs arise. Whether displacement arises in cases where there are no new needs remains a question that would benefit from further research. 


\section{References}

Adena, Maja and Anselm Hager, "Does Online Fundraising Increase Charitable Giving? A Nation-wide Field Experiment on Facebook," WZB Working Paper SP II 2020-302, 2020.

Andreoni, James and A. Abigail Payne, "Government Grants to Private Charities: Do They Crowd-Out Giving or Fund-raising?," American Economic Review, 2003, 93(3), 792812.

_ and _, "Is Crowding Out Due Entirely to Fundraising? Evidence from a Panel of Charities," Journal of Public Economics, 2011, 95(5-6), 334-343.

_ and _ , "Chapter 1 - Charitable Giving," Handbook of Public Economics, 2013, 5, 1-50.

_ , Justin M. Rao, and Hannah Trachtman, "Avoiding the Ask: A Field Experiment on Altruism, Empathy, and Charitable Giving," Journal of Political Economy, 2017, 125 (3), 625-653.

Auten, G.E., H. Sieg, and C.T. Clotfelter, "Charitable giving, income, and taxes: an analysis of panel data," The American Economic Review, 2002, 92 (1), 371-382.

Bakija, J.M., W.G. Gale, and J.B. Slemrod, "Charitable bequests and taxes on inheritances and estates: Aggregate evidence from across states and time," American Economic Review, 2003, 93 (2), 366-370.

Bakija, Jon and Bradley T. Heim, "How Does Charitable Giving Respond To Incentives And Income? New Estimates From Panel Data," National Tax Journal, 2011, 64(2), 61550 .

Bekkers, Rene, When and Why Matches Are More Effective Subsidies than Rebates

Bellemare, Marc F. and Casey J. Wichman, "Elasticities and the Inverse Hyperbolic Sine Transformation," Oxford Bulletin of Economics and Statistics, forthcoming.

Bergdoll, Jon, Chelsea Clark, Adriene Davis Kalugyer, Xiaonan (Coco) Kou, and Una Osili, “U.S. Household Disaster Giving in 2017 and 2018,” 2019.

Besley, Timothy and Robin Burgess, "The political economy of government responsiveness: Theory and evidence from India," The quarterly journal of economics, 2002, 117 (4), 1415-1451. 
Brown, Alexander, Jonathan Meer, and J. Forrest Williams, "Why Do People Volunteer? An Experimental Analysis of Preferences for Time Donations," Management Science, 2019, 65 (4), 1455-1468.

Brown, Philip H. and Jessica H. Minty, "Media Coverage and Charitable Giving after the 2004 Tsunami," Southern Economic Journal, 2008, 75 (1), 9-25.

Cairns, Jason and Robert Slonim, "Substitution effects across charitable donations," Economics Letters, 2011, 111 (2), 173-175.

Carlsson, Fredrik, Haoran He, and Peter Martinsson, "Easy come, easy go-The role of windfall money in lab and field experiments," Experimental Economics, 2013.

Chatterjee, Chandrayee, James C. Cox, Michael K. Price, and Florian Rundhammer, "Competition Among Charities: Field Experimental Evidence from a State Income Tax Credit for Charitable Giving," mimeo, 2020.

Chernozhukov, Victor, Mert Demirer, Esther Duflo, and Ivan Fernandez-Val, “Generic Machine Learning Inference on Heterogenous Treatment Effects in Randomized Experiments," NBER Working Paper No. 24678, 2018.

Cherry, Todd L, Peter Frykblom, and Jason F Shogren, "Hardnose the Dictator," American Economic Review, 2002, 92 (4), 1218-1221.

Cole, Shawn, Andrew Healy, and Eric Werker, "Do voters demand responsive governments? Evidence from Indian disaster relief," Journal of Development Economics, 2012, 97 (2), 167-181.

Corazzini, Luca, Christopher Cotton, and Paola Valbonesi, "Donor coordination in project funding: Evidence from a threshold public goods experiment," Journal of Public Economics, 2015, 128, 16 - 29.

Deck, Cary and James J. Murphy, "Donors Change Both Their Level and Pattern of Giving in Response to Contests Among Charities," European Economic Review, 2019, 112, 91-106.

DellaVigna, Stefano, James A. List, and Ulrike Malmendier, "Testing for Altruism and Social Pressure in Charitable Giving," The Quarterly Journal of Economics, 2012, 127(1), $1-56$.

Deryugina, Tatyana and Barrett Kirwan, "Does The Samaritan's Dilemma Matter? Evidence From US Agriculture," Economic Inquiry, 2018, 56 (2), 983-1006. 
_ , Garth Heutel, Nolan H. Miller, David Molitor, and Julian Reif, "The Mortality and Medical Costs of Air Pollution: Evidence from Changes in Wind Direction," American Economic Review, 2019, 109 (12), 4178-4219.

Drouvelis, Michalis, Adam Isen, and Benjamin M. Marx, “The Bonus-Income Donation Norm," CESifo Working Paper No. 7961, 2019.

Drury, A Cooper, Richard Stuart Olson, and Douglas A Van Belle, "The politics of humanitarian aid: US foreign disaster assistance, 1964-1995," The Journal of Politics, 2005, 67 (2), 454-473.

Eisensee, Thomas and David Strömberg, "News droughts, news floods, and US disaster relief," The Quarterly Journal of Economics, 2007, 122 (2), 693-728.

Ek, Claes, "Some causes are more equal than others? The effect of similarity on substitution in charitable giving," Journal of Economic Behavior E Organization, 2017, 136, 45-62.

Filiz-Ozbay, Emel and Neslihan Uler, "Demand for Giving to Multiple Charities: An Experimental Study," Journal of the European Economic Association, 2017.

Fong, Christina M and Erzo FP Luttmer, "What determines giving to Hurricane Katrina victims? Experimental evidence on racial group loyalty," American Economic Journal: Applied Economics, 2009, 1 (2), 64-87.

Garbarino, Ellen, Robert Slonim, and Carmen Wang, “The Multidimensional Effects of a Small Gift: Evidence from a Natural Field Experiment," Economics Letters, July 2013, $120(1), 83-61$.

Garrett, Thomas A and Russell S Sobel, "The political economy of FEMA disaster payments," Economic inquiry, 2003, 41 (3), 496-509.

Gee, Laura and Jonathan Meer, "The Altruism Budget: Measuring and Encouraging Charitable Giving," NBER Working Paper No. 25938, 2019.

Harwell, Haley, Adam Zindler, and Catherine Eckel., "Did the Ice Bucket Challenge Drain the Philanthropic Reservoir? Evidence from a Real-Donation Lab Experiment.," mimeo, 2020.

Healy, Andrew and Neil Malhotra, "Myopic voters and natural disaster policy," American Political Science Review, 2009, 103 (3), 387-406. 
Huck, Steffen and Imran Rasul, "Matched fundraising: Evidence from a natural field experiment," Journal of Public Economics, 2011, 95, 351-362.

_, - , and Andrew Shephard, "Comparing charitable fundraising schemes: Evidence from a field experiment and a structural model," American Economic Journal: Economic Policy, 2015, 7 (2), 326-69.

Kahneman, Daniel and Amos Tversky, "Choices, Values, and Frames," American Psychologist, 1984, 39, 341-350.

Karlan, Dean and John A. List, "Does Price Matter in Charitable Giving? Evidence from a Large-Scale Natural Field Experiment," American Economic Review, 2007, 97 (5), 17741793.

Lacetera, Nicola, Mario Macis, and Robert Slonim, "Will There Be Blood? Incentives and Displacement Effects in Pro-social Behavior," American Economic Journal: Economic Policy, 2012, 4 (1), 186-223.

Landry, Craig E., Andreas Lange, John A. List, Michael K. Price, and Nicholas G. Rupp, "Toward an Understanding of the Economics of Charity: Evidence from a Field Experiment," The Quarterly Journal of Economics, 2006, 121(2), 747-782.

${ }_{-},,_{-},,_{-}$, and $\ldots$, "Is a Donor in Hand Better Than Two in the Bush? Evidence from a Natural Field Experiment," American Economic Review, 2010, 100(3), 958-83.

List, John A., “The Market for Charitable Giving," Journal of Economic Perspectives, 2011, 25 (2).

List, John A and David Lucking-Reiley, "The effects of seed money and refunds on charitable giving: Experimental evidence from a university capital campaign," Journal of Political Economy, 2002, 110 (1), 215-233.

Meer, Jonathan, "Does fundraising create new giving?," Journal of Public Economics, 2017, $145,82-93$.

- and Benjamin Priday, "Generosity Across the Income and Wealth Distributions," mimeo, 2020.

Petrova, Maria, Ricardo Perez-Truglia, Andrei Simonov, and Pinar Yildirim, "Are Political and Charitable Giving Substitutes? Evidence from the United States," NBER Working Paper No. 26616, 2020. 
Randolph, W.C., "Dynamic income, progressive taxes, and the timing of charitable contributions," The Journal of Political Economy, 1995, 103 (4), 709-738.

Reinstein, David, "Substitution among charitable contributions: An experimental study," Unpublished manuscript, 2012.

Reinstein, David A, "Does one charitable contribution come at the expense of another?," The BE Journal of Economic Analysis \& Policy, 2011, 11 (1).

Reinstein, David and Gerhard Riener, "Decomposing desert and tangibility effects in a charitable giving experiment," Experimental Economics, Mar 2012, 15 (1), 229-240.

Rose-Ackerman, Susan, "Charitable Giving and Excessive Fundraising," Quarterly Journal of Economics, 1982, 96, 193-212.

_ , "Ideals vs. Dollars: Donors, Charity Managers, and Government Grants," Journal of Political Economy, 1987, 95, 810-823.

Scharf, Kimberley A, Sarah Smith, and Mark Wilhelm, "Lift and Shift: The Effect of Fundraising Interventions in Charity Space and Time," 2017.

Schmitz, Jan, "Is Charitable Giving a Zero-Sum Game? The Effect of Competition between Charities on Giving Behavior," mimeo, 2019.

Shang, Jen and Rachel Croson, "A Field Experiment in Charitable Contribution: the Impact of Social Information on the Voluntary Provision of Public Goods," Economic Journal, 2009, 119, 1422-1439.

Simon, Matt, "Why It's So Hard to Predict Where a Tornado Will Strike," 2019. https://www.wired.com/story/why-its-so-hard-to-predict-where-a-tornadowill-strike/.

Strömberg, David, "Natural disasters, economic development, and humanitarian aid," The Journal of Economic Perspectives, 2007, pp. 199-222.

Thaler, Richard H., "Mental Accounting and Consumer Choice," Marketing Science, 1985, $27,15-25$.

_ , "Mental Accounting Matters," Journal of Behavioral Decision Making, 1999, 12, 183-206.

Tibshirani, Robert, "Regression shrinkage and selection via the lasso," Journal of the Royal Statistical Society: Series B (Methodological), 1996, 58 (1), 267-288. 
Tversky, Amos and Daniel Kahneman, "The Framing of Decisions and the Psychology of Choice," Science, 1981, 211, 453-458. 


\section{Appendix A: Additional Figures and Tables}

Figure A.1: Fatalities and injuries caused by tornadoes, by month (2002-2017)

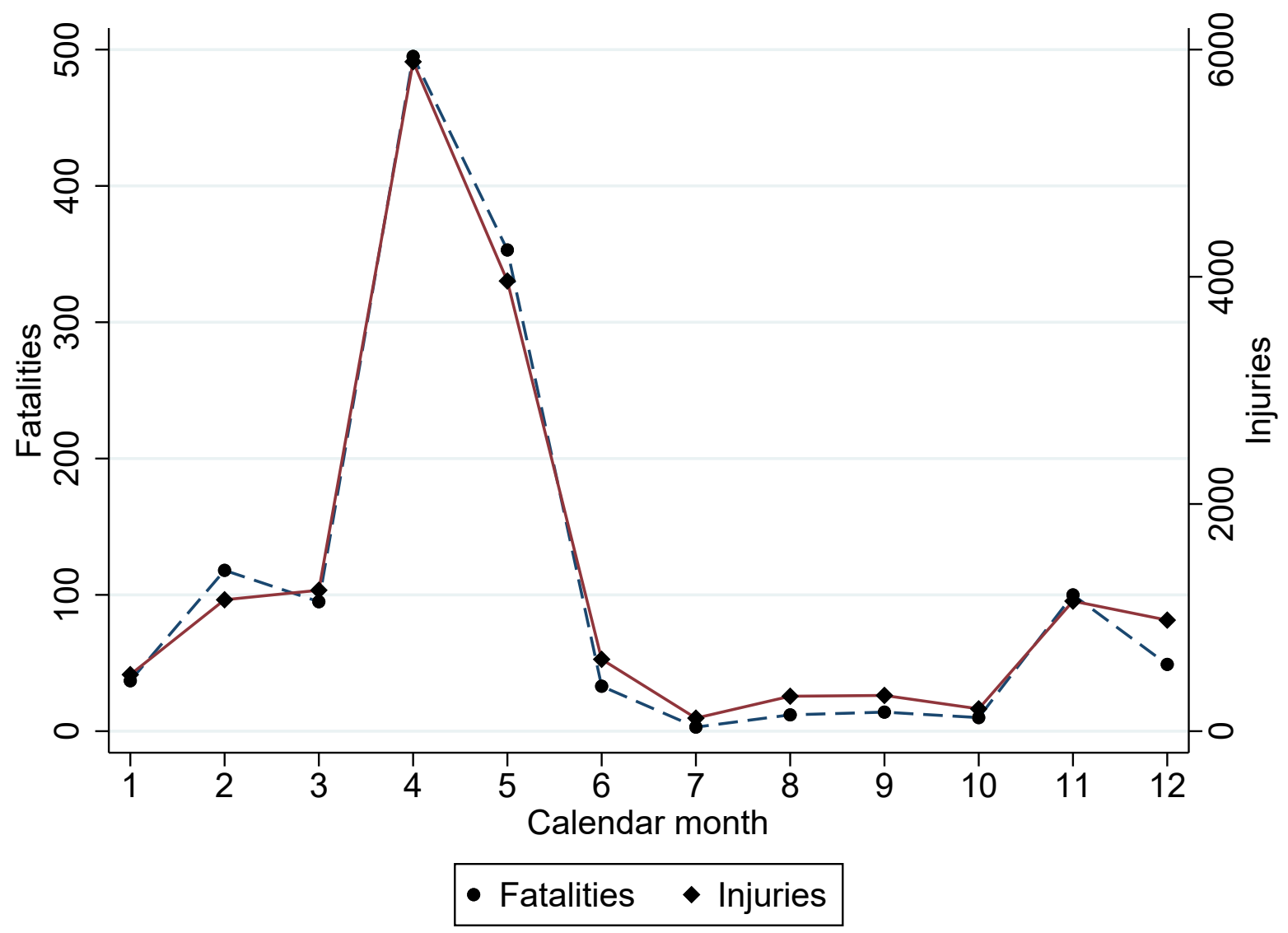

Source: NOAA. Black circles connected by the dashed blue line correspond to the total number of tornadocaused fatalities in a given month over the time period 2002-2017. The scale for fatalities is indicated by the left y-axis. Black diamonds connected by the solid red line correspond to the total number of tornadocaused injuries in a given month over the time period 2002-2017. The scale for injuries is indicated by the right y-axis. 
Table A.1: The effect of tornadoes on the number of returns claiming charitable donations (income tax data)

$(1)$

\begin{tabular}{lccc}
\hline Fatalities within 20-100 miles & $\begin{array}{c}0.0007 \\
(0.0012)\end{array}$ & \\
In-state fatalities, 20-100 miles & & 0.0014 & \\
& & $(0.0016)$ & 0.0017 \\
In-state fatalities, 20+ miles & & & $(0.0016)$ \\
& & & \\
\hline Observations & 329,589 & 329,589 & 329,589 \\
AIC & -639434 & -639452 & -639509 \\
\hline
\end{tabular}

Notes: The table reports estimates of equation (1). The dependent variable is the inverse hyperbolic sine of the total number of returns claiming charitable donations. Standard errors (in parentheses) are clustered by state. ${ }^{* * *} \mathrm{p}<0.01,{ }^{* *} \mathrm{p}<0.05,{ }^{*} \mathrm{p}<0.10$.

Table A.2: The effect of tornadoes on Adjusted Gross Income and the number of returns (income tax data)

\begin{tabular}{lcccccc}
\hline & \multicolumn{3}{c}{ Adjusted Gross Income } & \multicolumn{3}{c}{ Number of returns } \\
& $(1)$ & $(2)$ & $(3)$ & $(4)$ & $(5)$ & $(6)$ \\
\hline Fatalities, 20-100 miles & 0.0001 & & & -0.0001 & \\
& $(0.0012)$ & & & $(0.0005)$ & \\
In-state fatalities, 20-100 miles & & -0.0003 & & & 0.0003 \\
& & $(0.0014)$ & & & $(0.0007)$ & \\
In-state fatalities, 20+ miles & & & 0.0005 & & & 0.0001 \\
& & & $(0.0017)$ & & & \\
& & & & & & \\
\hline Observations & & & & & \\
AIC & 368,045 & 368,045 & 368,045 & 368,045 & 368,045 & 368,045 \\
Mean of dependent variable & -307862 & -307862 & -307864 & -942140 & -942142 & -942140 \\
& 19.22 & 19.22 & 19.22 & 8.432 & 8.432 & 8.432 \\
\hline
\end{tabular}

Notes: The table reports estimates of equation (1). The dependent variable is the inverse hyperbolic sine of the variable specified above each column. Standard errors (in parentheses) are clustered by state. ${ }^{* * *} \mathrm{p}<$ $0.01,{ }^{* *} \mathrm{p}<0.05,{ }^{*} \mathrm{p}<0.10$. 
Table A.4: The effect of tornadoes on donations to all causes, common sample (income tax data)

\begin{tabular}{lcccccc}
\hline & $(1)$ & $(2)$ & $(3)$ & $(4)$ & $(5)$ & $(6)$ \\
\hline Fatalities, 20-100 miles & 0.0019 & 0.0019 & & & & \\
& $(0.0009)^{* *}(0.0009)^{* *}$ & & & & \\
Fatalities, 0-20 miles & \multicolumn{2}{c}{0.0004} & & & & \\
& & $(0.0014)$ & & & & \\
In-state fatalities, 20-100 miles & & & 0.0030 & 0.0029 & & \\
& & & $(0.0013)^{* *}$ & $(0.0013)^{* *}$ & 0.0026 & 0.0025 \\
In-state fatalities, 20+ miles & & & & & $(0.0011)^{* *}$ & $(0.0011)^{* *}$ \\
& & & & 0.0008 & & 0.0011 \\
In-state fatalities, 0-20 miles & & & & $(0.0013)$ & & $(0.0014)$ \\
& & & & & & \\
\hline Observations & 331,269 & 331,269 & 331,269 & 331,269 & 331,269 & 331,269 \\
AIC & -264201 & -264199 & -264222 & -264220 & -264241 & -264240 \\
Effect (\$1000s) of 1 add'1. fatality & 1101 & 1081 & 1228 & 1198 & 1958 & 1920 \\
\hline
\end{tabular}

Notes: The table reports estimates of equation (1). The dependent variable is the inverse hyperbolic sine of donations. The sample is restricted to years that appear in both the income-tax and charity datasets: 2002 and 2004-2016. Standard errors (in parentheses) are clustered by state. ${ }^{* * *} \mathrm{p}<0.01,{ }^{* *} \mathrm{p}<0.05,{ }^{*} \mathrm{p}<0.10$.

Table A.3: The effect of tornadoes on donations to all causes (placebo test)

\begin{tabular}{lccc}
\hline & $(1)$ & $(2)$ & $(3)$ \\
\hline Lead of fatalities within 20-100 miles & -0.0022 & & \\
Lead of in-state fatalities, 20-100 miles & $(0.0013)$ & & \\
& & -0.0025 & \\
Lead of in-state fatalities, 20+ miles & & $(0.0017)$ & -0.0009 \\
& & & $0.0011)$ \\
& & & \\
\hline Observations & 303,330 & 303,330 & 303,330 \\
Controls & $X$ & $X$ & $X$ \\
AIC & -275281 & -275280 & -275255 \\
Effect (\$1000s) of add'l. fatality & -1257 & -1037 & -706.6 \\
\hline
\end{tabular}

Notes: The table reports estimates of equation (1). The dependent variable is the inverse hyperbolic sine of donations. Standard errors (in parentheses) are clustered by state. ${ }^{* * *} \mathrm{p}<0.01,{ }^{* *} \mathrm{p}<0.05,{ }^{*} \mathrm{p}<0.10$. 
Table A.5: The effect of past and contemporaneous tornadoes on donations to all causes (income tax data)

\begin{tabular}{|c|c|c|c|c|c|c|}
\hline & (1) & (2) & (3) & (4) & (5) & (6) \\
\hline Fatalities, 20-100 miles & $\begin{array}{c}0.0016 \\
(0.0010)^{*}\end{array}$ & $\begin{array}{c}0.0016 \\
(0.0009)^{*}\end{array}$ & & & & \\
\hline Fatalities, $20-100$ miles, lagged & $\begin{array}{c}0.0008 \\
(0.0008)\end{array}$ & $\begin{array}{c}0.0006 \\
(0.0008)\end{array}$ & & & & \\
\hline Fatalities, 0-20 miles & & $\begin{array}{c}0.0005 \\
(0.0014)\end{array}$ & & & & \\
\hline Fatalities, 0-20 miles, lagged & & $\begin{array}{c}0.0019 \\
(0.0009)^{* * *}\end{array}$ & & & & \\
\hline In-state fat., 20-100 miles & & & $\begin{array}{c}0.0030 \\
(0.0014)^{* *}\end{array}$ & $\begin{array}{c}0.0029 \\
(0.0014)^{* *}\end{array}$ & & \\
\hline In-state fat., 20-100 miles, lagged & & & $\begin{array}{c}0.0013 \\
(0.0011)\end{array}$ & $\begin{array}{c}0.0011 \\
(0.0011)\end{array}$ & & \\
\hline In-state fat., $20+$ miles & & & & & $\begin{array}{c}0.0027 \\
(0.0013)^{* *}\end{array}$ & $\begin{array}{c}0.0026 \\
(0.0012)^{* *}\end{array}$ \\
\hline In-state fat., $20+$ miles, lagged & & & & & $\begin{array}{c}0.0015 \\
(0.0010)\end{array}$ & $\begin{array}{c}0.0014 \\
(0.0010)\end{array}$ \\
\hline In-state fat., 0-20 miles & & & & $\begin{array}{c}0.0009 \\
(0.0012)\end{array}$ & & $\begin{array}{c}0.0011 \\
(0.0014)\end{array}$ \\
\hline In-state fat., 0-20 miles, lagged & & & & $\begin{array}{l}0.0021 \\
(0.0010)^{* *}\end{array}$ & & $\begin{array}{c}0.0019 \\
(0.0010)^{*}\end{array}$ \\
\hline Observations & 327,937 & 327,937 & 327,937 & 327,937 & 327,937 & 327,937 \\
\hline AIC & -266674 & -266676 & -266700 & -266703 & -266732 & -266734 \\
\hline Effect (\$1000s) of add'l. fatality & 930.8 & 907.5 & 1200 & 1167 & 2043 & 2003 \\
\hline
\end{tabular}

Notes: The table reports estimates of equation (1). The dependent variable is the inverse hyperbolic sine of donations. Standard errors (in parentheses) are clustered by state. ${ }^{* *} \mathrm{p}<0.01,{ }^{* *} \mathrm{p}<0.05,{ }^{*} \mathrm{p}<0.10$. 
Table A.6: The effect of tornadoes on contributions received by distant charities, common sample (charities tax data)

$(1)$

0.0016

(0.0011)

In-state fatalities, 20-100 miles

0.0002

$(0.0011)$

In-state fatalities, $20+$ miles

$\begin{array}{lcc}\text { Fatalities, 20-100 miles } & 0.0016 & \\ \text { In-state fatalities, } 20-100 \text { miles } & (0.0011) & 0.0002 \\ & & (0.0011)\end{array}$

0.0013

$(0.0012)$

\begin{tabular}{llll}
\hline Observations & $2,965,367$ & $2,965,367$ & $2,965,367$ \\
\hline
\end{tabular}

Notes: The table reports estimates of equation (1). The dependent variable is the inverse hyperbolic sine of contributions received. The sample is restricted to years that appear in both the income-tax and charity datasets: 2002 and 2004-2016. Standard errors (in parentheses) are clustered by state. ${ }^{* * *} \mathrm{p}<0.01,{ }^{* *} \mathrm{p}<0.05$, ${ }^{*} \mathrm{p}<0.10$.

Table A.9: The effect of tornadoes on contributions received by distant charities, binary treatment variable (charities tax data)

\begin{tabular}{|c|c|c|c|c|c|}
\hline & (1) & (2) & (3) & $(4)$ & (5) \\
\hline Any in-state fatalities, $20-100$ miles & $\begin{array}{c}0.0017 \\
(0.0024)\end{array}$ & $\begin{array}{c}0.0018 \\
(0.0022)\end{array}$ & $\begin{array}{c}0.0035 \\
(0.0023)\end{array}$ & $\begin{array}{l}-0.0087 \\
(0.0055)\end{array}$ & $\begin{array}{c}0.0044 \\
(0.0204)\end{array}$ \\
\hline Observations & $3,162,513$ & $1,416,807$ & $1,416,807$ & $1,445,290$ & $1,445,291$ \\
\hline EIN-by-ZIP fixed effects & $X$ & $X$ & $X$ & & \\
\hline 3-digit ZIP time trends & $X$ & $X$ & & & \\
\hline 3-digit ZIP fixed effects & & & & $X$ & \\
\hline State fixed effects & & & & & $X$ \\
\hline Restricted to ever-treated & & $X$ & $X$ & $X$ & $X$ \\
\hline
\end{tabular}

Notes: The table reports estimates of equation (1) with an indicator for any fatal tornado within 20-100 miles as the key independent variable. The dependent variable is the inverse hyperbolic sine of contributions received. The included controls are indicated in the table. Standard errors (in parentheses) are clustered by state. ${ }^{* * *} \mathrm{p}<0.01,{ }^{* *} \mathrm{p}<0.05,{ }^{*} \mathrm{p}<0.10$.

- Charity Robustness: control variables

- Charity robustness: dropping larger organizations 
Table A.7: The effect of tornadoes on contributions received by distant charities (charities tax data)

(1) (2)

(2) (3)

(4)

Panel A

\begin{tabular}{lcccc}
\hline Fatalities, 20-100 miles & 0.0014 & 0.0015 & 0.0013 & 0.0015 \\
& $(0.0012)$ & $(0.0012)$ & $(0.0012)$ & $(0.0013)$ \\
& & & & \\
\hline Observations & $3,162,513$ & $3,130,445$ & $3,002,224$ & $2,842,188$ \\
Largest percentile included & 100 & 99 & 95 & 90 \\
\hline
\end{tabular}

Panel B

\begin{tabular}{|c|c|c|c|c|}
\hline In-state fatalities, $20-100$ miles & $\begin{array}{c}0.0000 \\
(0.0011)\end{array}$ & $\begin{array}{l}-0.0000 \\
(0.0011)\end{array}$ & $\begin{array}{c}-0.0005 \\
(0.0011)\end{array}$ & $\begin{array}{l}-0.0007 \\
(0.0012)\end{array}$ \\
\hline Observations & $3,162,513$ & $3,130,445$ & $3,002,224$ & $2,842,188$ \\
\hline Largest percentile included & 100 & 99 & 95 & 90 \\
\hline \multicolumn{5}{|c|}{ Panel C } \\
\hline In-state fatalities, $20+$ miles & $\begin{array}{c}0.0010 \\
(0.0012)\end{array}$ & $\begin{array}{c}0.0010 \\
(0.0012)\end{array}$ & $\begin{array}{c}0.0006 \\
(0.0012)\end{array}$ & $\begin{array}{c}0.0007 \\
(0.0012)\end{array}$ \\
\hline Observations & $3,162,513$ & $3,130,445$ & $3,002,224$ & $2,842,188$ \\
\hline Largest percentile included & 100 & 99 & 95 & 90 \\
\hline
\end{tabular}

Notes: The table reports estimates of equation (1). The dependent variable is the inverse hyperbolic sine of contributions received. Standard errors (in parentheses) are clustered by state. ${ }^{* * *} \mathrm{p}<0.01,{ }^{* *} \mathrm{p}<0.05$, ${ }^{*} \mathrm{p}<0.10$. 
Table A.8: Heterogeneity in the effect of tornadoes on contributions received by distant charities (charities tax data)
(1)
(2)
(3)

\begin{tabular}{|c|c|c|c|}
\hline Human services * Fatalities, $20-100$ miles & $\begin{array}{c}-0.0003 \\
(0.0024)\end{array}$ & & \\
\hline Safety and disaster ${ }^{*}$ Fatalities, $20-100$ miles & $\begin{array}{c}0.0037 \\
(0.0074)\end{array}$ & & \\
\hline Other types * Fatalities, $20-100$ miles & $\begin{array}{c}0.0016 \\
(0.0012)\end{array}$ & & \\
\hline Human services * In-state, $20-100$ miles & & $\begin{array}{c}0.0003 \\
(0.0022)\end{array}$ & \\
\hline Safety and disaster * In-state, 20-100 miles & & $\begin{array}{l}-0.0062 \\
(0.0085)\end{array}$ & \\
\hline Other types * In-state, $20-100$ miles & & $\begin{array}{c}0.0001 \\
(0.0013)\end{array}$ & \\
\hline Human services ${ }^{*}$ In-state, $20+$ miles & & & $\begin{array}{c}0.0015 \\
(0.0023)\end{array}$ \\
\hline Safety and disaster * In-state, $20+$ miles & & & $\begin{array}{c}0.0028 \\
(0.0084)\end{array}$ \\
\hline Other types ${ }^{*}$ In-state, $20+$ miles & & & $\begin{array}{c}0.0008 \\
(0.0011)\end{array}$ \\
\hline Observations & $3,162,513$ & $3,162,513$ & $3,162,513$ \\
\hline
\end{tabular}

Notes: The table reports estimates of equation (1). The dependent variable is the inverse hyperbolic sine of contributions received. Standard errors (in parentheses) are clustered by state. ${ }^{* * *} \mathrm{p}<0.01,{ }^{* *} \mathrm{p}<0.05$, ${ }^{*} \mathrm{p}<0.10$. 
Figure A.2: Bootstrap results for ratio of displacement to charitable response

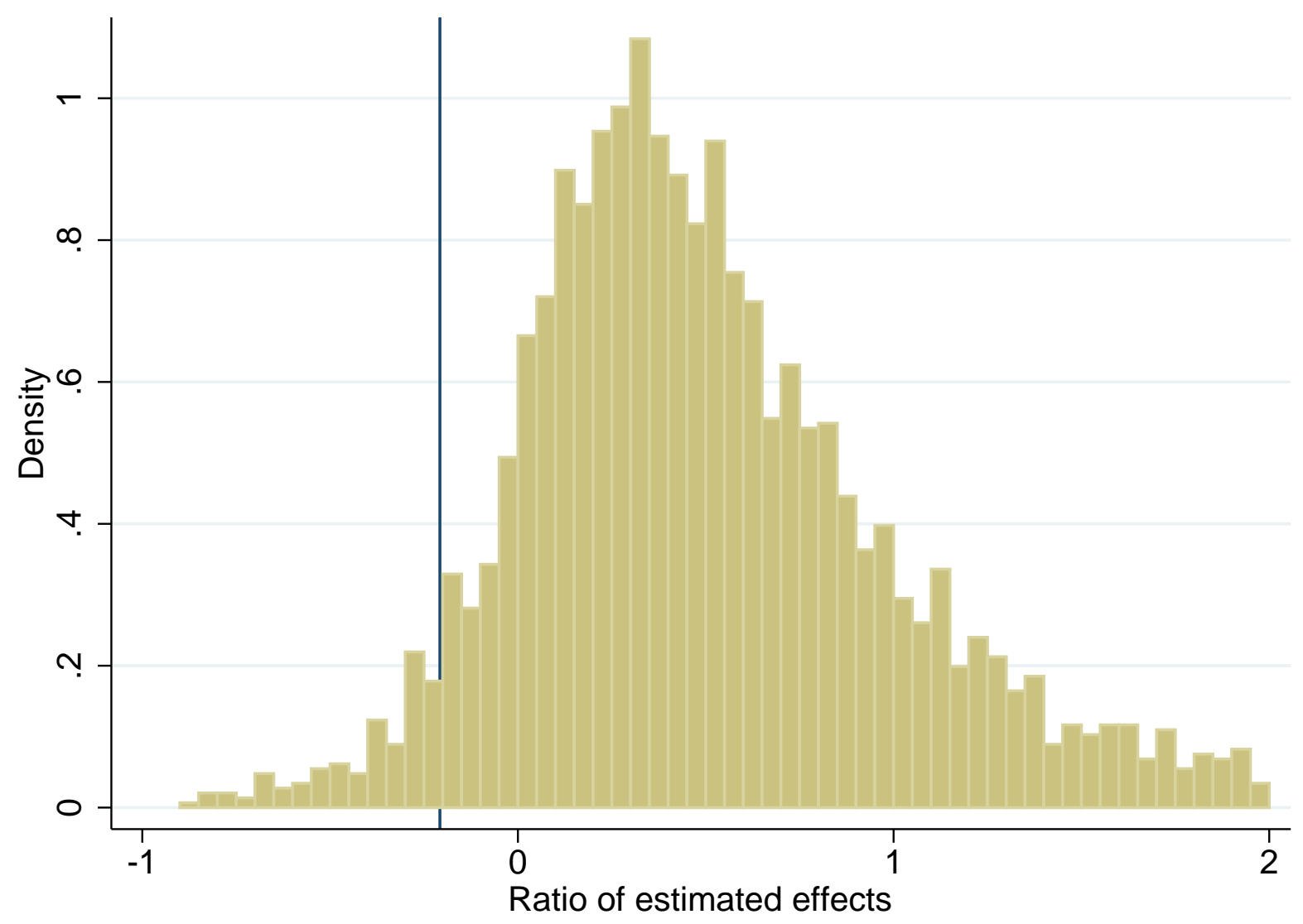

Notes: Distribution of the ratio of effects on charities to effects on total giving claimed for tax deductions. We ran 3,194 bootstrap iterations. Vertical line placed at the 5th percentile of the estimates. 


\section{Appendix B: Heterogeneous Effects on Charities}

While we find no displacement effect on average, there may be particular types of charities that lose donations as a result of increased donations to tornado victims and their service providers. To assess the answer to this question, we employ the machine-learning method proposed by Chernozhukov et al. (2018) (hereafter "CDDF") to estimate heterogeneous treatment effects.

\section{Methodology}

CDDF propose a method for estimating heterogeneous treatment effects in the context of randomized controlled trials, and this method has been applied to a quasi-experimental setting by Deryugina et al. (2019). The basic approach is to first train a machine-learning algorithm to predict the outcome of interest separately for treated and control observations as a function of covariates. Conditional on these covariates, differences between the predictions of the treated outcome and the control outcome form a proxy predictor, which can then be used to characterize the distribution of treatment effects and to compare the characteristics of groups that are affected to a greater extent with those of groups that are affected to a lesser extent. Any machine-learning algorithm can be used for the prediction, and we use Lasso Tibshirani (1996). To avoid overfitting, we first randomly partitioned the data into an auxiliary sample and a main sample. The algorithm is trained on the auxiliary sample and then applied to the main sample to provide predicted treatment effects, and these can then be compared with the results of regressions using the main sample. The partitioning of the data into these two samples introduces additional variation that can be addressed by repeating the entire procedure to obtain confidence intervals. Following the recommendation of CDDF, we repeated the procedure 100 times.

Our setting is amenable to the CDDF method with some changes from our main specification. We restrict the sample to exclude observations within 20 miles of a fatal tornado, as before, but to speed computation and make the control group more similar in sample size to the treatment group, we also exclude organizations that are never located within 100 miles of a fatal tornado. Then, because the treatment must be binary, we study an indicator for having any fatalities caused by tornadoes that struck between 20 and 100 miles away in the same state-year (rather than the number of such fatalities). The results reported in Appendix Table A.9 show no significant average treatment effects with this binary variable, just as with our continuous measures, implying that the estimates of the average treatment effects are robust to the restriction to the subsample of charities that are ever located within 100 miles of a fatal tornado. This yields 1,391,445 observations, of 
which 15.1 percent are treated with proximity to a fatal tornado and 84.9 serve as the control group. As our covariates, we use ventiles of organization size, indicators for the major NTEE categories describing organizational mission, and the ZIP Code shares of several demographic groups in the year-2000 decennial Census. ${ }^{22}$ We include fixed effects for the state, the year, and the month in which the fiscal year ends 23

Unlike in a randomized controlled trial, the propensity score in our setting is not known. We therefore estimate it using Lasso and the same set of predictors used to train the main machine-learning models. To reduce noise, we omit observations with propensity scores below 0.05 or above 0.95 . We then use the main sample to estimate regressions of the form

$\operatorname{asinh}\left(\operatorname{cont}_{i t}\right)=\alpha+\beta_{1}\left(T_{i t}-\hat{p}\left(Z_{i t}\right)\right)+\beta_{2}\left(T_{i t}-\hat{p}\left(Z_{i t}\right)\right)\left(\hat{S}\left(Z_{i t}\right)-\overline{\hat{S}}\right)+\beta_{3} \operatorname{asinh}\left(\operatorname{cont}_{i t}\right)+\varepsilon_{i t}$.

As in previous regressions, the outcome $\operatorname{asinh}\left(\right.$ cont $\left._{i t}\right)$ is the asinh of contributions received. In this regression, $T_{i t}$ is the treatment indicator for a fatal tornado striking between 20 and 100 miles away in a given state, and $\hat{p}\left(Z_{i t}\right)$ is the estimated propensity score denoting the predicted probability of treatment. $\hat{S}\left(Z_{i t}\right)$ is a prediction of the treatment effect for an observation, which is obtained by taking the difference between its predicted outcome using the treatment-trained model and its predicted outcome using the control-trained model. $\overline{\hat{S}}$ is the average value of $\hat{S}\left(Z_{i t}\right)$ across the main sample. We include the control-group prediction, $\operatorname{asinh}\left(\right.$ cont $\left._{i t}\right)$, to improve precision. Observations in this regression are weighted by $w\left(Z_{i t}\right)=\frac{1}{\hat{p}\left(Z_{i t}\right)\left(1-\hat{p}\left(Z_{i t}\right)\right)}$. Estimates of the parameter $\beta_{1}$ describe the average treatment effects that we previously estimated with equation (1). The parameter of interest here is $\beta_{2}$, which provides a joint test of whether there is heterogeneity in the treatment effects and whether that heterogeneity is captured by the proxy predictor $\hat{S}\left(Z_{i t}\right)$.

\footnotetext{
${ }^{22}$ Organization size is measured by expenses at the time of an organization's first appearance in the data. The Census demographic characteristics are White, Black, urban, minor, senior, college degree holder, foreign born, and aggregate income in 1999 for the population aged 15 years and over, all of which we scale by year-2000 population. The NTEE categories are Arts, Culture \& Humanities; Education; Environment; Animal-Related; Health Care; Mental Health \& Crisis Intervention; Voluntary Health Associations \& Medical Disciplines; Medical Research; Crime \& Legal-Related; Employment; Food, Agriculture \& Nutrition; Housing \& Shelter; Public Safety, Disaster Preparedness \& Relief; Recreation \& Sports; Youth Development; Human Services; International, Foreign Affairs \& National Security; Civil Rights, Social Action \& Advocacy; Community Improvement \& Capacity Building; Philanthropy, Voluntarism \& Grantmaking Foundations; Science \& Technology; Social Science; Public \& Societal Benefit; Religion-Related; Mutual \& Membership Benefit; and Unknown.

${ }^{23}$ Fixed effects for smaller geographic units, as in our regressions in which we estimated average effects, were not computationally feasible. As seen in Appendix Table A.9. our main regression estimates become less precise with state fixed effects, but point estimates remain close to zero.
} 
We also estimate

$$
\left.\operatorname{asinh}\left(\operatorname{cont}_{i t}\right)=\alpha+\sum_{q=1}^{5}\left[\gamma_{q}\left(T_{i t}-\hat{p}\left(Z_{i t}\right)\right) \cdot \mathbf{1}_{q}\right]+\beta \operatorname{asinh} \hat{(\operatorname{cont}} t_{i t}\right)+\varepsilon_{i t}
$$

This equation reveals the average treatment effects $\gamma_{q}$ among each of the groups signified by the indicator function $\mathbf{1}_{q}$ for observations falling into quantiles $q$ of the proxy predictor $\hat{S}\left(Z_{i t}\right)$. If there is predictable heterogeneity in the treatment effects, then the treatment effects $\gamma_{q}$ in the main sample should be increasing in $q$. Such estimates can be obtained for any partition of the sample. For our question regarding whether some charities are significantly negatively affected, we break the distribution up into five equally sized groups, i.e. quintiles. The rest of the variables and regression weights are as defined in equation 2.

\section{Results}

The machine-learning approach shows little evidence of charities that suffer when donors give to tornado victims. First, we estimate $\hat{\beta}_{2}=0.147$ (with standard error 0.131 ). This estimate indicates that a one percent increase in a predicted treatment effect is associated with an insignificant 0.11 percent increase in an estimated treatment effect. This implies that if there are heterogeneous effects of deadly tornadoes on contributions to charities located 20 to 100 miles away, then this heterogeneity is not predictable based on state, year, charity size, or charity mission.

Figure B.1 shows the estimates from equation 3 and their confidence intervals. The estimates are all close to zero, and none is statistically significant. The estimate for the most negatively affected fifth of organizations is -0.03 , implying that a deadly tornado strike that occurs 20-100 miles away reduces contributions by less than half of one percent ${ }^{24}$ The point estimate for the top fifth of organizations is positive and almost as large in absolute value as the negative estimate for the bottom fifth.

\footnotetext{
${ }^{24}$ For the asinh-linear specification with large values of the outcome variable, evaluating the elasticity at the sample mean of 0.151 fatal tornadoes yields $\varepsilon \approx-0.03 * 0.151 \approx-0.0045$.
} 
Figure B.1: Heterogeneous treatment effects on charities

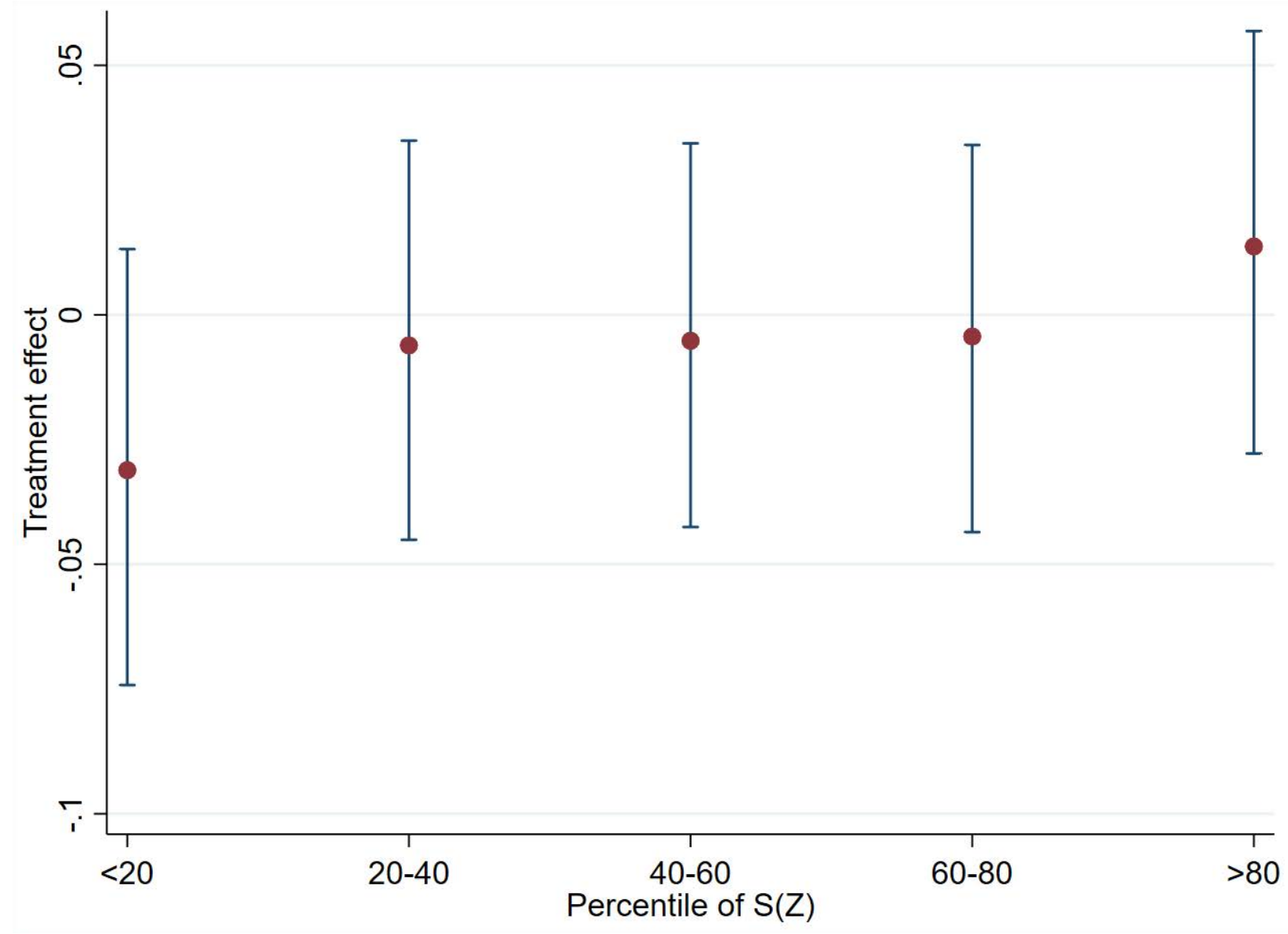

Estimates of equation 3, using the machine-learning method of Chernozhukov et al. (2018). 